\author{
Classification \\ Physics Abstracts \\ $81.15 \mathrm{H}$
}

\title{
Surface structure and topography of vapour deposited carbon investigated by scanning tunneling microscopy
}

\author{
Ann-Sofie Norekrans and Jan-Otto Carlsson \\ Uppsala University, Institute of Chemistry, Thin Film and Surface Chemistry Group, Box 531, \\ S-751 21 Uppsala, Sweden
}

(Received October 01, 1990; accepted January 04, 1991)

\begin{abstract}
Résumé. - Dans les processus de déposition atomique, la structure et la topographie de la surface et les marches en surface influencent fortement le mécanisme de croissance et les propriétés du matériau déposé. Cependant, structure, densité de marches et topographie résultent aussi du procédé de déposition. De ce fait, l'étude des surfaces à l'échelle atomique indique à la fois les caractéristiques du processus de dépôt et du mécanisme de croissance. La Microscopie Tunnel à Balayage a été utilisée pour caractériser la topographie de la surface et la structure des films de carbone. Ces films sont formés par déposition chimique en phase vapeur (CVD) à partir de méthane ou d'éthène à des temperatures respectivement de 1030 a $1080^{\circ} \mathrm{C}$ et 800 a $1050^{\circ} \mathrm{C}$. Les substrats sont des plaquettes monocristallines de saphir. La topographie de la surface augmente avec le temps de dépôt et approche asymptotiquement une limite de $100 \AA$ qui est indépendante de la température de croissance et du précurseur. Les conditions de déposition pour des films de $500 \AA$ d'épaisseur ont permis d'obtenir une topographie de moins de $50 \AA$. Le microscope est utilisé aussi avec une résolution proche de la résolution atomique. Des parties de surface avec des arrangements désordonnés ou ordonnés d'atomes de carbone ont été reconnues. Les zones ordonnées sont très petites (autour de $10 \AA$ ) et l'arrangement des atomes ressemble à celui du graphite.
\end{abstract}

\begin{abstract}
In atomistic deposition processes the surface structure, the surface steps and the surface topography strongly influence the growth behaviour and thus the properties of the deposited material. However, the structure, the step density and the topography are at the same time the result of the deposition process itself. Hence surface investigation on the atomic level will reveal characteristics of the deposition process and of the growth mechanisms. Scanning tunneling microscopy (STM) was used to characterize the surface topography and structure of carbon films. The films were deposited by chemical vapour deposition (CVD) from methane or ethene at temperatures ranging from 1030 to $1080^{\circ} \mathrm{C}$ and from 800 to $1050^{\circ} \mathrm{C}$, respectively. Monocrystalline (012) sapphire wafers were used as substrates. The surface topography increased with deposition time and approached asymptotically a limit value of $100 \AA$, which was independent of the growth temperature as well as of the precursor used. For $500 \AA$ thick films deposition conditions yielding a topography less than $50 \AA$ could be found. The microscope could also be operated close to atomic resolution. Surface areas with both ordered and disordered carbon atoms were then detected. The areas with the ordered atoms were very small (about $10 \AA$ ). The atomic arrangement within these areas resembled that of graphite.
\end{abstract}




\section{Introduction.}

In atomistic deposition processes surface characteristics such as structure, step configuration, step density and topography strongly influence the growth behaviour and thus the properties of the deposited material. However, during the deposition the surface characteristics usually change and become a result of the deposition process. For a deeper understanding of growth processes in general surface investigations on the atomic level are required. Such investigations may give information on the growth mechanism(s). Scanning tunneling microscopy (STM) $[1,2]$ is a technique covering the whole range of geometrical surface characteristics from $\AA$ (surface structure and steps) to $\mu \mathrm{m}$ (topography, grains, grain boundaries,...) [3]. Hence STM is a very attractive technique for a general surface characterization.

Vapour deposited carbon or pyrolytic carbon has a unique combination of properties including both mechanical strength and heat conduction. It is also a highly attractive biocompatible material and might be used in biosensor applications. Ion-selective electrodes, used in analytical chemistry, is another field where pyrolytic carbon is of interest. Of particular interest is miniaturized devices in carbon (biosensors and microelectrodes). Normally patterning by lithographic technique is needed for the miniaturization. This requires smooth surfaces for production of very small feature sizes.

Pyrolytic carbon is favourably grown by Chemical Vapour Deposition (CVD) from a gaseous hydrocarbon $[4,5]$. The hydrocarbon is then introduced into a reactor. On or in the vicinity of the heated substrate surface, chemical reactions, generating solid carbon, occur. The threshold temperature for the carbon deposition is strongly influenced by the thermochemical stability of the precursor used. For instance for benzene and methane, deposition temperatures of about 600 and $1000^{\circ} \mathrm{C}$ respectively, are needed. The atomic arrangement of the CVD carbon is strongly affected by the deposition temperature and the deposition rate $[4,5]$. For high temperatures, e.g., $2200^{\circ} \mathrm{C}$, and low pressures, e.g., $10 \mathrm{Torr}$, an anisotropic material, pyrolytic graphite, is grown. The structure of pyrolytic carbon is similar to that of graphite with parallel basal but disordered planes with a spacing between the planes which is somewhat longer (about $0.1 \AA$ ) than that in graphite. This structure is called turbostatic [4]. For lower deposition temperatures and/or higher deposition rates the disorder increases and the preferred orientation decreases. Finally, amorphous carbon is formed at low deposition temperatures and high deposition rates.

The aim of this investigation was to study the influence of the deposition conditions on the surface topography of CVD carbon and in favourable cases also determine the atomic arrangement in the surface. STM is the only technique that can be used for such an investigation.

\section{Experimental.}

2.1 Deposition. - A horizontal hot wall quartz reactor was used for the deposition experiments. The gas flows were maintained constant using mass flow controllers. The leak rate of air into the system was approximately $1 \times 10^{-5} \mathrm{Torr} \cdot 1 \cdot \mathrm{s}^{-1}$, corresponding to an air impurity level in the system of $10 \mathrm{ppm}$. The carbon films were deposited from methane (purity $99.99 \%$ ) or ethene (purity $99.95 \%$ ) and $\mathrm{Ar}$ (purity $99.9997 \%$ ) was used as carrier gas. Depending on the thermal stability of the hydrocarbons employed, an extremely low gas flow velocity, $0.7 \mathrm{~cm} \cdot \mathrm{s}^{-1}$, had to be used to localize the deposition to the centre of the hot wall reactor. This flow velocity corresponds to a residence time of the molecules in the hot zone of about half a minute. The other deposition conditions are summarized in table I. Prior to the deposition experiments, the substrates were cleaned in $\mathrm{NH}_{4} \mathrm{OH} / \mathrm{H}_{2} \mathrm{O}_{2}(2.5 \% / 6 \%)$ and $\mathrm{HCl} / \mathrm{H}_{2} \mathrm{O}_{2}(3.7 \% / 6 \%)$ water solutions [6]. 
Table I. - Deposition conditions.

\begin{tabular}{|c|c|c|}
\hline Precursor & Methane & Ethene \\
\hline Substrate & (012) sapphire wafers & (012)sapphire wafers \\
\hline Reaction gas flow (sccm) & 5 & 5 \\
\hline Carrier gas flow $(\mathrm{sccm})$ & 95 & 95 \\
\hline Deposition time(min) & $15-300$ & $5-60$ \\
\hline Total pressure (Torr) & 380 & 380 \\
\hline Deposition temperature $\left({ }^{\circ} \mathrm{C}\right)$ & $1030-1080$ & $800-1050$ \\
\hline
\end{tabular}

2.2 MATERIALS CHARACTERIZATION. - The surface chemical composition of the grown films were determined by ESCA (AlK $\alpha$ radiation) and by Auger electron spectroscopy (AES) (PerkinElmer 5500). Phase analysis was performed by means of X-ray diffraction (Philips powder X-ray diffractometer) using $\mathrm{CuK} \alpha$ radiation.

2.3 FILM THICKNESS MEASUREMENTS. - The film thickness was determined after local laser etching of the carbon films. Thin 50-150 $\mu \mathrm{m}$ wide grooves were etched in the films through focusing the beam of an $\operatorname{ArF}^{*}$ excimer laser $(\lambda=193 \mathrm{~nm}$; pulse length $=17 \mathrm{~ns})$ by means of a quartz cylindrical lens onto the sample surface. A sequence of pulses (5-20 depending on the thickness of the film, and the laser fluence) was used for complete removal of the layer. The substrate was not affected, since it was transparent for this wavelength. The depth of the etched grooves was measured with a profilometer (Alpha-step 200). A detailed investigation of the etching process is in progress.

2.4 STM AND SURFACE TOPOGRAPHY MEASUREMENTS. - A commercial Digital Instruments NanoscopeI was used for the STM measurements [7]. Vibration isolation was provided by placing the microscope on a cement block from a tripod by elastic bands. The images were taken at room temperature and at atmospheric pressure in the constant current mode. The bias used was $0.025 \mathrm{~V}$ and the current $2.0 \mathrm{nA}$. The tips, Pt-Ir (90/10), were formed mechanically. The topography was measured from the STM images at different locations on the substrate surface and the mean topography was calculated from at least 15 individual points of measurements.

\section{Results and discussion.}

3.1 SURFACE TOPOGRAPHY. - No surface impurities on the carbon films were detected in neither the ESCA spectrum nor the AES spectrum. The peaks had profiles typical of graphitic carbon. The X-ray diffractogram showed one broad peak at a $d$-value of $3.46 \AA$, which is characteristic for pyrolytic carbon [4].

The film thickness increases linearly with time irrespective of the carbon precursor used (see Figs. 1a and 1b). The deposition rate also increases with increasing temperature (see Figs. 2a and 2b). For the methane process an activation energy of $620 \mathrm{~kJ} / \mathrm{mole}$ was obtained, while the ethene based process yielded an activation energy of $250 \mathrm{~kJ} / \mathrm{mole}$. The latter activation energy is in agreement with published data [8], while the published activation energies for methane decomposition are considerably lower $(420 \mathrm{~kJ} / \mathrm{mole})[9]$.

STM images showing the surface topography of carbon films deposited from methane and ethene, respectively are depicted in figures 3 and 4. 

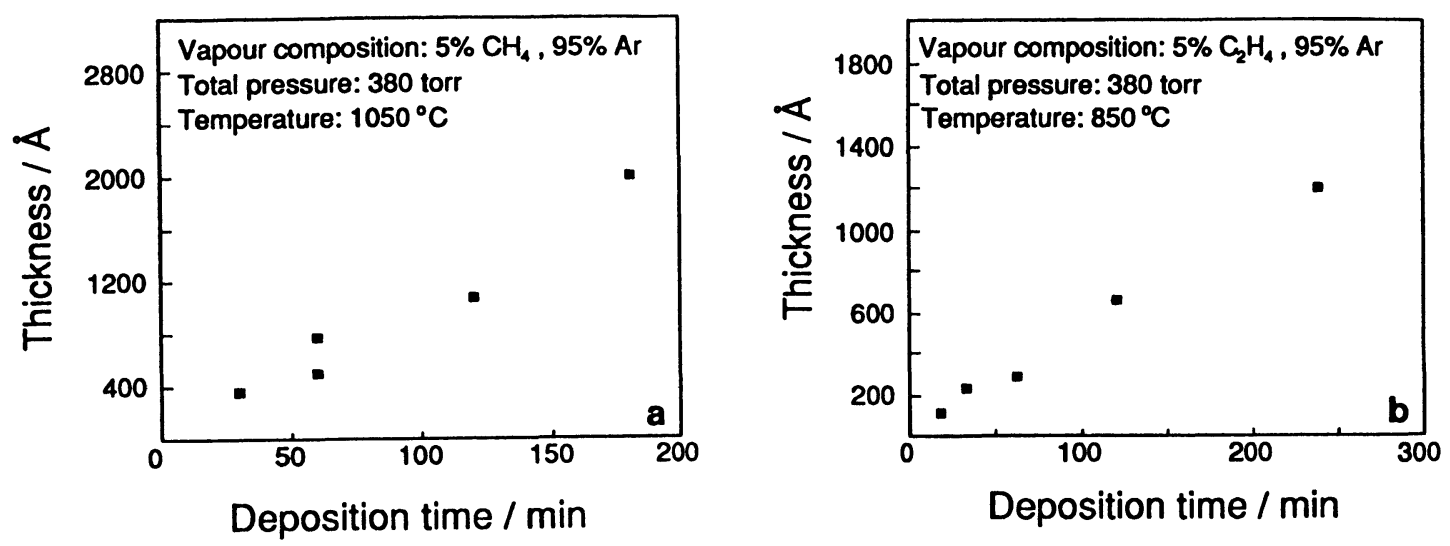

Fig. 1. - Film thickness as a function of deposition time when methane (a) and ethene (b) are used as precursors.
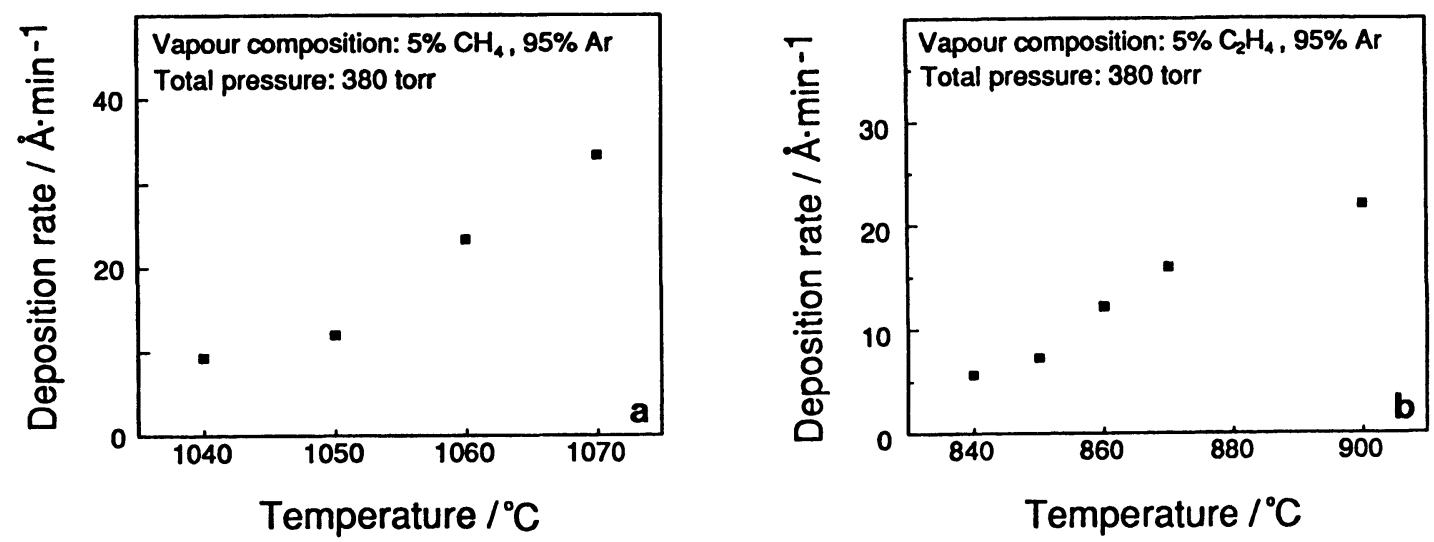

Fig. 2. - Influence of temperature on the deposition rate when methane (a) and ethene (b) are used as precursors.

The evolution of the topography with time for films deposited from methane at the same temperature are displayed in figures $3 a$ and $3 b$. With increased deposition time or increased film thickness the topography becomes more pronounced. The influence of temperature on the topography upon deposition from ethene for a fixed deposition time (30 minutes) can be seen in the figures $4 \mathrm{a}$ and $4 \mathrm{~b}$. Also with increased temperature a thicker film is obtained and hence the topography increases.

The surface topography approaches asymptotically a limit value (see Figs. 5a and 5b). The temperature influences only slightly the topography (Figs. 5c and 5d). A steady-state topography close to $100 \AA$ seems to be developed even if the deposition temperature differs by more than $100^{\circ} \mathrm{C}$. This correlates also quite well with the lateral dimensions of the islands formed, which are the same for both the methane and the ethene samples.

The surface topography is principally the result of two fluxes; the impingement flux of the carbon atoms towards the surface (deposition rate) and the surface diffusion flux. The impingement 

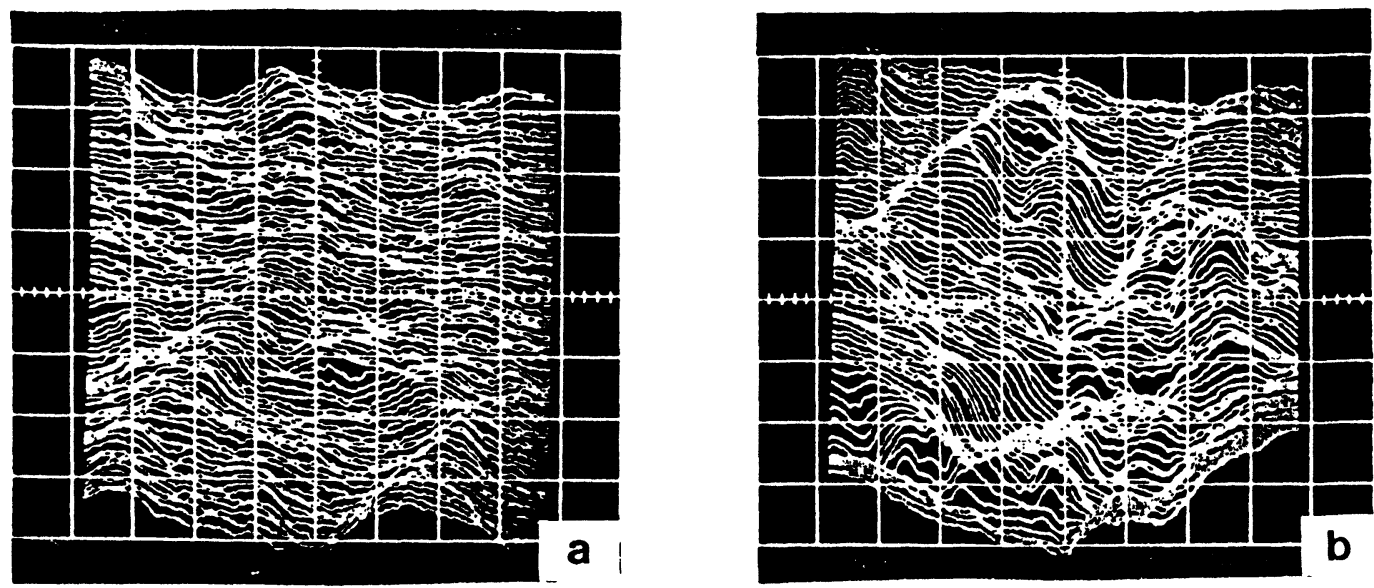

Fig. 3. - STM images showing the surface topography of carbon films deposited from methane at $1050{ }^{\circ} \mathrm{C}$ at different deposition times, 15 minutes (a) and 180 minutes (b), respectively. $x$-scale $=250 \AA /$ div, $y$-scale $=$ $250 \AA / \mathrm{div}, z$-scale $=60 \AA / \mathrm{div}$.
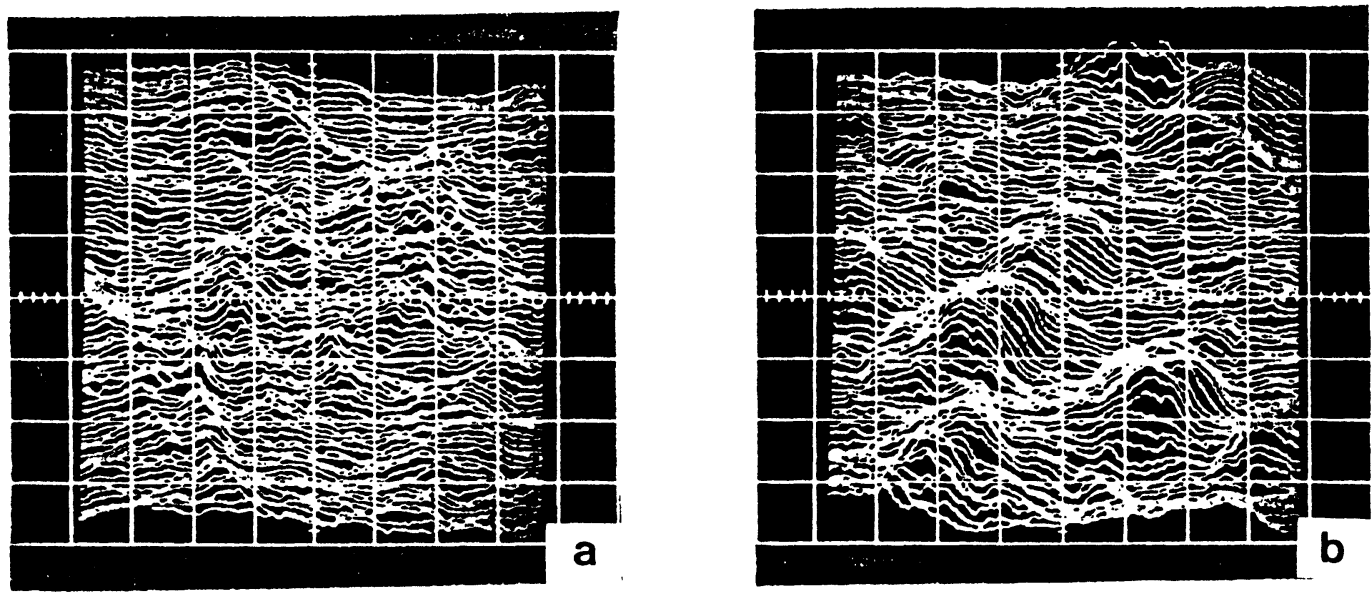

Fig. 4. - STM images showing the surface topography of carbon films deposited from ethene during 30 minutes at two different temperatures, $830^{\circ} \mathrm{C}$ (a) and $870{ }^{\circ} \mathrm{C}$ (b), respectively. $x$-scale $=250 \AA /$ div, $y$-scale $=250 \AA / \mathrm{div}, z$-scale $=60 \AA / \mathrm{div}$.

flux defines the surface diffusion time and hence the surface diffusion length. At the initial stages of growth, both the impingement flux and the surface diffusion flux are usually not the same as those later on when the substrate surface is covered by an intact film. The mean distance between the nuclei, which is the capture radius of the nuclei, is given by half the surface diffusion length under the specific deposition conditions. Usually the initial nucleus density defines the grain size later on in the film. In the case of carbon the nucleus density, with topographic feature sizes of about $250 \AA$, is about $10^{11}$ nuclei/ $\mathrm{cm}^{2}$. This nucleus density is reasonable for the deposition conditions used in this investigation. However, it can not be excluded that secondary nucleation might 

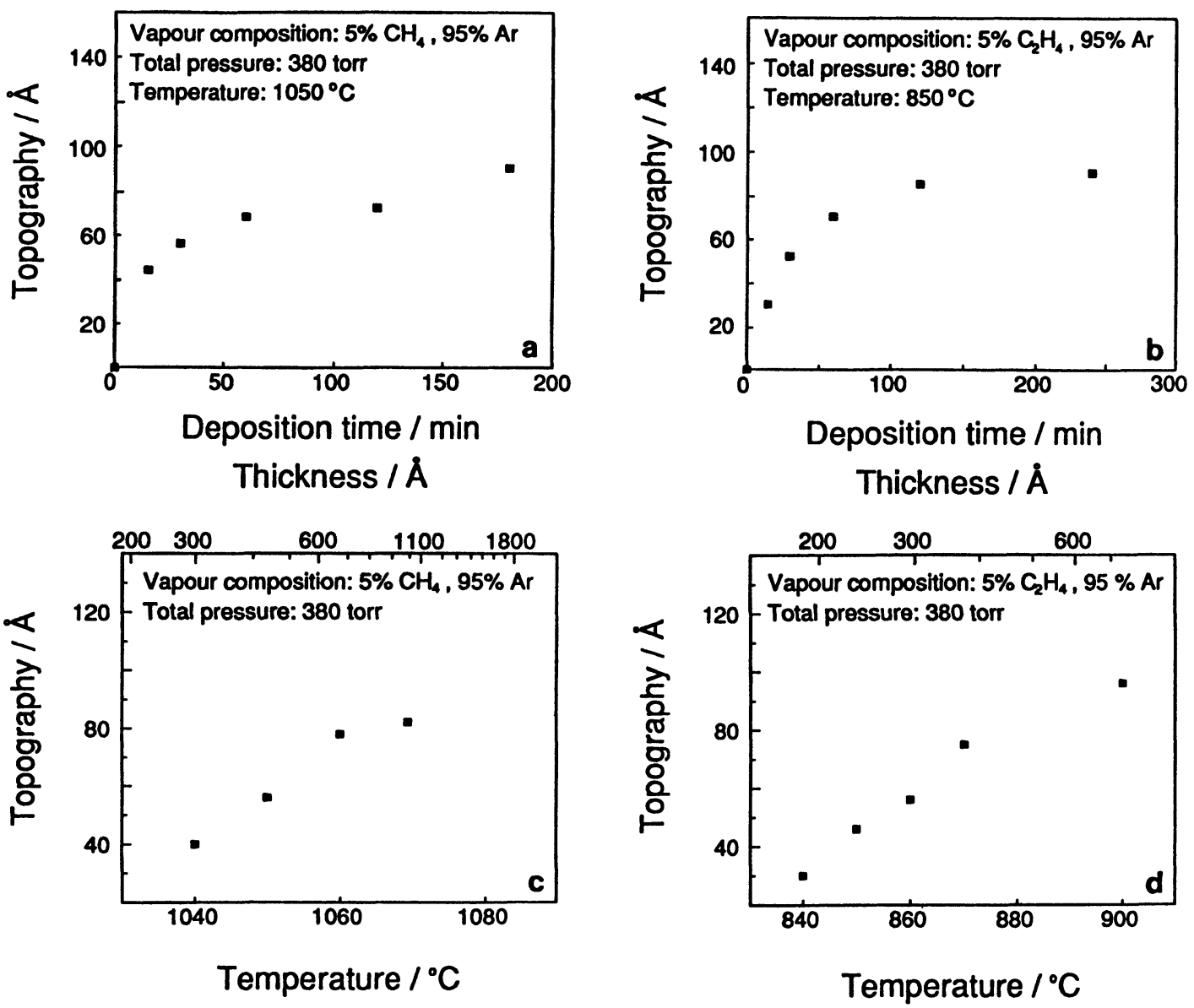

Fig. 5. - Topography dependence of deposition time (a,b) and of temperature (c,d).

have occured later on in the deposition process. This means that the surface diffusion conditions and hence the surface diffusion lengths are changed during the deposition process. However, the fact that the topography always approaches asymptotically a maximum value indicates that steadystate conditions with a constant surface diffusion length or a constant surface diffusion flux has been reached. Within the accuracy of the measurements, the steady-state conditions seem to be independent of the temperature. This is somewhat surprising. Usually the surface diffusion increases with increasing temperature provided that the diffusing species and the surface structure are the same in the whole temperature range. In this case the surface structure as well as probably the diffusing species are changed with the temperature. With a lower temperature the surface structure becomes more amorphous and the diffusing species probably more hydrogen rich. Both these effects increase the surface mobility of the carbon-carrying species in comparison with the case of the same surface structure and the same diffusing species throughout the whole temperature range.

3.2 SURFACE STRUCTURE. - Highly oriented pyrolytic graphite (HOPG) was used to check the atomic resolution of the microscope. Atomic resolution images of very good quality were then 
obtained. For the deposited carbon films, atomic resolution could not be achieved. However, figure 6 shows a picture close to atomic resolution. Small areas of ordered carbon atoms could be identified. The bumps in the picture corresponds to the second-neighbour atoms [10]. The distance between the carbon atoms in these areas were, within the accuracy of the measurement, the same as the distance measured between the carbon atoms in HOPG (2.46 $\AA)$. The majority of the carbon surface was built up of disordered atoms. This is expected at the low deposition temperatures used. The X-ray diffractogram also showed the typical peak of pyrolytical carbon.

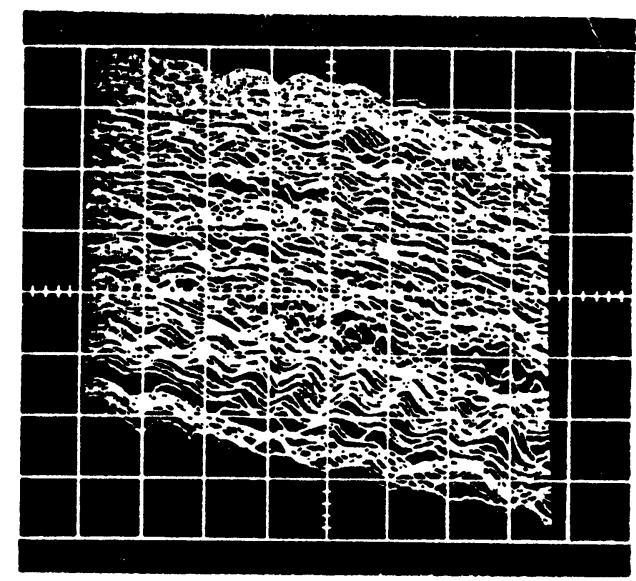

Fig. 6. - STM image of nearly atomic resolution showing the ordered and disordered areas of carbon atoms. $x$-scale $=2.8 \AA / \mathrm{div}, y$-scale $=2.8 \AA / \mathrm{div}, z$-scale $=3.0 \AA / \mathrm{div}$.

It is not surprising that the graphite-like surface structure can be found in small surface areas (approximate size $10 \AA$ ). With increasing deposition temperature the graphitic areas can be assumed to expand at the expense of the amorphous regions. For temperatures above $2000^{\circ} \mathrm{C}$ and low deposition rates a structure very close to graphite, turbostatic, is formed. The present investigation clearly shows that the graphite embryos are generated at temperatures below $1000^{\circ} \mathrm{C}$.

\section{Conclusions.}

The surface topography of vapour deposited films is controlled by two fluxes: the impingement flux and the surface diffusion flux. For carbon films the surface topography reached a maximum value of about $100 \AA$. This value was independent of the deposition temperature and of the precursor used. However, the time needed to reach the steady-state or maximum topography was dependent on the deposition conditions. For $500 \AA$ thick carbon films a surface topography less than $50 \AA$ can be achieved with a proper selection of deposition conditions. Such a small topography allows patterning of the deposited films in the submicron range.

Traces of graphite-like structure was found in small surface areas (about $10 \AA$ in size). However, even if not fully atomic resolution could be reached in the STM images it is concluded that carbon deposited at low temperatures consists of a large fraction of amorphous carbon but with small islands of ordered carbon atoms. Finally, this work has shown that the STM technique is very 
useful to characterize vapour deposited materials in a wide resolution range. Moreover, it reveals details in the surface structure which can not be studied with any other technique.

\section{Acknowledgements.}

Financial support provided by the Swedish Natural Science Research Council and the Swedish Board for Technical Development is gratefully acknowledged. The authors are also indebted to Dr. Peter Mogyorósi for technical assistance in the laser etching.

\section{References}

[1] Binnig G. and RoHrer H., Surf. Sci. 126 (1983) 236-244.

[2] Binnig G., Fuchs H., Gerber CH., ROHRER H., StOll E. and TOSATTI E., Europhys. Lett. 1 (1986) 31-36.

[3] Hansma P. and Tersoff J., J. Appl. Phys. 61 (1987) R1-R23.

[4] BlOCHER Jr J. M., J. Vac. Sci. Technol, 11 (1974) 680-686.

[5] BoKROS J. C., Chemistry and Physics of Carbon, Marcel Dekker, N. Y., 5 (1969) 1-118.

[6] KERN W. and PUOTINEN D. A. RCA Rev., (1970) 187-206.

[7] NANOSCOPE I, Digital Instruments Inc., Goleta, CA 93117.

[8] Molear M. J. and StubBS F. J., J. Chem. Soc. (1952) 381-391.

[9] Lieberman M. L., Nucl. Sci. Abs. 30 (1974) 34522, or Sandia Lab. Internal Report SLA-74-0233 (1974).

[10] PARK S.-I. and QuATE C. F., Appl. Phys. Lett. 48 (1986) 112-114. 